\title{
An Unidentified Monster in the Bed - Assessing Nocturnal Asthma in Children
}

\author{
Darrell Ginsberg*
}

\begin{abstract}
Nocturnal asthma (NA) is increasing in prevalence, affecting millions of people worldwide. In addition to being associated with increased mortality, NA is associated with a decreased quality of life. NA associated sleep disturbances and increased daytime sleepiness are especially important in children due to the accompanying behavioral and developmental difficulties. As diurnal spirometry is not a practical tool for the diagnosis and monitoring of NA, self or parental reports are used. Children underreport and underestimate their NA symptoms and parents are not fully aware of their child's NA indicators. In addition, there is the lack of physician familiarity regarding the assessment and treatment of NA. Therefore, NA is chronically underreported. The development of a non-invasive, objective, home-based diagnostic tool is crucial in diagnosing and monitoring children with NA. The presence of wheeze during sleep has been successfully employed as a tool to measure NA in children. This review discusses the increasing prevalence of NA, current diagnostic tools and the consequences of undiagnosed NA in children. In conclusion, this paper suggests that an automated wheeze detective device is an objective and practical tool to aid the diagnosis and monitoring of NA.
\end{abstract}

KEYWORDS: Nocturnal asthma, Sleep disturbances, Children, Wheeze

\section{INTRODUCTION}

Approximately 300 million people worldwide suffer from asthma with the prevalence increasing by $50 \%$ each decade (1). In children, asthma is the most common chronic illness worldwide (2). Nocturnal asthma (NA) is defined as any nighttime worsening of reversible airway disease associated with an increase in symptoms and airway responsiveness (3). NA symptoms, such as awakenings, cough, wheeze and dyspnea were reported in $47-75 \%$ of asthma patients in a number of extensive surveys from different countries (4-6). Objectively, NA is defined as a diurnal reduction in forced expiratory volume in one second (FEV1) of greater than $15 \%$ (7). However, as will be discussed in this review, acquiring diurnal spirometric data for the diagnosis and management of NA is difficult, timeconsuming and expensive. Therefore, NA is usually

*To whom correspondence should be addressed:

Darrell Ginsberg,

Department of Cellular Biology and Anatomy

Technion - Israel Institute of Technology

Faculty of Medicine Rappaport Building

7 Rehov Efron, Bat Galim, Haifa

E-mail: Ginsberg@tx.technion.ac.il identified and monitored by nocturnal symptoms, increased nighttime asthma medication and daytime sequela.

\section{SOURCES OF NOCTURNAL ASTHMA}

A specific cause of NA has not yet been clearly defined. NA has the characteristics of a circadian disorder, a sleep-related induction of asthma and a more severe form of asthma. While everyone experiences a circadian-based nadir in lung function in the early morning, patients with NA experience a greater than normal diurnal decrease in airway function independent of sleep. The three main features of asthma - airway obstruction, inflammation and bronchial hyperresponsiveness - are all linked to a circadian nadir at 4 am $(8,9)$. This suggests the influence of circadian rhythms causing the nocturnal impairment of lung function (10). In addition, sleep can exacerbate lung function aggravation $(11,12)$. Confounding factors associated with sleep, such as the supine position of sleep and sleep-related disorders - i.e. Gastroesophageal Reflux Disease (GERD) or Obstructive Sleep Apnea (OSA) - worsen the lung function of asthmatics during sleep and hinder the determination of 
the role of sleep in NA (13-17). Increased asthma severity does correlate with a greater risk of NA, but NA is not dependent on severe asthma (18-20). Interestingly, a specific polymorphism of the $\square 2$ adrenergic receptor has been linked with NA, but not with more severe asthma, indicating the role of genetics in NA $(21,22)$. The mechanism of this polymorphism's correlation to NA has not been elucidated $(22,23)$. Additionally, exogenous triggers such as allergens and non-allergic stimuli may provoke NA.The origin of NA is not yet known; however it is likely multi-factorial and based on the patient's unique genetic, physical and environmental characteristics.

\section{LINK TO MORTALITY}

NA is linked to an increased risk of mortality, with $70 \%$ of deaths and $80 \%$ of respiratory arrests caused by asthma occurring during nocturnal hours $(24,25)$. A large nocturnal variation in peak expiratory flow (PEF), as observed in NA, is not correlated with asthma severity. However, it is an independent risk factor for respiratory arrest (24). This demonstrates that NA, independent of asthma severity, is correlated with asthma-related mortality. In a 7-year follow up study of Italian young adults with asthma, NA symptoms such as nocturnal dyspnea and nocturnal tightness were correlated with a two-fold increase in subsequent overall mortality (26). Additionally, a Canadian casecontrol study demonstrated an increased risk of mortality for asthmatics with nocturnal symptoms (27). NA patients have been found to have 5-to-6 times more risk of accidental death than the general population, which may be attributed to nocturnal symptoms interfering with their daytime attentiveness (26). In addition, nocturnal oxygen disruptions resulting from NA lead to an increased production of potentially dangerous free radicals (28). Therefore NA must be treated as a serious chronic disorder as it is correlated to an increased rate of mortality.

\section{INCREASING PREVALENCE OF ASTHMA}

Asthma has been increasing worldwide and based on the increase of two correlating factors, obesity and oldage, it is likely to continue increasing (29-31). Obesity has been shown to be associated with an increased risk of asthma in both children and adults $(32,33)$. As the incidence of obesity in children and adults rises, asthma rates are expected to increase $(34,35)$. Additionally, NA has been reported to be more prevalent in the elderly (36). The percentage of the elderly population worldwide is expected to continue to rise in the coming years as the baby boomer generation ages and medical advances allow for longer lives (37). Moreover, an increase in childhood asthma symptoms has been observed in recent years and is expected to continue $(38,39)$. In accordance, Garner and Kohen found an increasing incidence of childhood asthma in Canadian children aged 0-5 and 10-11 (40). Whether this increased prevalence is based on an improvement in a physician's ability to diagnose asthma or a rise in the causes of asthma is unknown. It is important to consider the vast majority of information on asthma prevalence in children comes from epidemiological studies involving school-based surveys. In developing countries this would institute a sampling bias as many children from lower-income families do not attend school or go home early to help provide for the family. Compounding this, socioeconomic status is negatively correlated with asthma severity and nocturnal symptoms (41). Thus, the rates of asthma may be higher than reported in developing countries. As the number of asthmatics rise, tools for effective diagnosis and monitoring of NA symptoms will become increasingly vital.

\section{UNIQUE MECHANISM OF NOCTURNAL ASTHMA}

Diurnal FEV1 is an objective test for NA, though it does not account for subjective symptoms. Morgan et al. reported that the FEV1 of NA patients was on average $31 \%$ lower in the early morning than in the previous afternoon, but no detectable changes in the respiratory rate or expiratory duration were found during sleep (42). This demonstrates that the NA patient may not take action during sleep to compensate for a lack of oxygen. This can lead the asthmatic to undergo intermittent or acute hypoxia which can increase the levels of reactive oxygen species (ROS) leading to pathological effects $(28,43)$. Additionally, nocturnal asthmatics do not undergo the normal asthmatic adaptive response of increasing lung volume to combat increased airway resistance and maintain airway patency (44). This relationship does occur in asthmatics without NA and in non-asthmatics, indicating a unique mechanism of bronchoconstriction in NA (44).

\section{DIURNAL SPIROMETRY TO ASSESS NOCTURNAL ASTHMA}

The gold standard for the identification of asthma is clinical history, physical examination and laboratory spirometry with challenge testing. Spirometry demands a skilled technician to guide technique and interpret results. It is impractical for a technician to collect the required nighttime and morning spirometric data to accurately assess NA. To overcome this problem, the European Respiratory Society recommended day-today home spirometry for child asthmatics to measure 
variation in pulmonary function (45). Initially, mechanical meters were used and the patient was instructed to fill out a diurnal PEF diary. However, it was demonstrated that written PEF diaries were unreliable $(46,47)$. Electronic home spirometry devices that automatically record data were employed to combat this issue. However, the spirometric data had poor concordance with other parameters of asthma severity and thus was deemed not clinically useful (48). Additionally, home spirometry compliance and test performance varies greatly in children, providing a biased picture of changes in lung function (49). Home spirometry is also impractical for children, as it requires extensive training and follow-up to ensure proper testing technique (50). At present, there is no practical way to collect a child asthmatic's diurnal spirometric data.

\section{SELF AND PARENTAL QUESTIONNAIRES TO ASSESS NOCTURNAL ASTHMA}

The simplest and most common method of assessing NA is self-completed questionnaires. Selfidentification of NA symptoms is very difficult since the patient must clearly understand the meaning of the questions posed towards them regarding wheezing, coughing and sleep disturbances and be conscious of their nighttime symptoms (51). Falconer et al. found that adults have poor agreement between subjective self-estimation and objective measurements of nocturnal cough, a common symptom of NA (52). Physicians are often unaware of their patients' NA symptoms as patients generally have an indifferent view of NA symptoms and do not regularly report them to their doctor (53). In their study of 13,493 asthmatics, Raherison et al. found that only $48 \%$ had agreement between their actual NA situation and what was recorded by their general practitioner (6). Moreover, $42 \%$ of patients who declared they had no nocturnal symptoms had NA according to objective tests (6). This demonstrates a striking inability of the patient and the doctor to declare and identify NA symptoms. Identification of NA is vital as patients with NA symptoms have the lowest awareness of inadequate asthma control (54). Children have more difficulty in self-diagnosing NA than adults, as they are generally less aware of indicators (55). Physicians must be aware of this and specifically question asthma patients, especially children, regarding their NA status.

For children, parental reports/questionnaires are often employed in addition to self-diagnosis (51). Cultural and educational conditions play an important role in the answering of these questionnaires $(56,57)$. Parents must understand the terms used to describe NA symptoms and literacy is required to complete questionnaires. Parents often do not know when their child falls asleep, are unaware of most awakenings and are not able to identify nighttime wheeze (58). Less than $40 \%$ of parents with a child who is asthmatic report their child's NA symptoms appropriately (18). Moreover, NA is more prevalent and asthma more severe in areas of low socioeconomic status, possibly due to environmental factors (41). Parents in these areas are more likely to have lower literacy rates of the national language (59). Low parental literacy correlates directly with worse care measures for children with asthma possibly due to a lack of understanding of asthma symptoms and lack of ability to report symptoms to a physician (60). As such, the risk of underdiagnosis and undertreatment of asthma was higher in children from ethnic minority groups in the inner-city and from poorer neighborhoods (61). Parents of children at higher risk of developing NA due to environmental and socioeconomic factors do not accurately report their child's asthmatic status (62).

The accuracy of self-diagnostic questionnaires to identify and monitor a child's NA status has not been confirmed. Regarding daytime symptoms, selfquestionnaires in children aged 7-12 are as accurate in diagnosing asthmatics as objective tests such as bronchial hyper-responsiveness testing (63). Additionally, recent research suggests child asthmatics as young as 7 dependably report their asthmatic status (64). However, no studies have specifically researched self-diagnostic questionnaires to identify and monitor NA. Nocturnal symptoms are associated with future asthmatic severity (65). Self-diagnostic questionnaires do not predict future asthmatic episodes in children under the age of 11, suggesting that these questionnaires may not be suitable to monitor NA (66). Sleep arousals are hard to self-diagnose as the child may have trouble remembering and reporting awakenings $(67,68)$. For example, Brooke et al. found poor agreement between recorded and recalled nighttime coughing in child asthmatics (69). In a study of students aged $10-12,21 \%$ were not able to answer if they had nocturnal cough (70).

Generally, children report more asthma symptoms than their parents (70-73). Mallol et al. demonstrated that adolescents report higher symptoms of asthma, rhinitis, and eczema related symptoms than parentallycompleted questionnaires (51). Sleep disturbance symptoms such as cough at night and awakening with wheezing during the past 12 months were reported significantly higher by the child than the parent (51). Nocturnal cough is reported significantly more by the child than by the parent (70). This is understandable since the child is more aware of their nighttime disturbances than the parent and may not necessarily 
share this information with the parent. Parents of children over the age of 11 provide little to no more asthma information than is obtained through a child's self-assessment (74).

The lack of understanding of the term 'wheeze' in children impairs accurate diagnosis and asthma control. Riedler et al. reported difficulty for adolescents in understanding the term 'wheeze' (75). The difficulty in diagnosing wheeze is not limited to children. Levy et al. demonstrated that during daytime hours parents are unable to accurately assess the severity of their child's wheezing as compared to a physician or a computerized-acoustic analysis (58). In a study of India's physicians, a substantial percentage $(33 \%)$ did not identify wheeze when shown in the International Study of Asthma and Allergies in Childhood ISAAC video sequences (76). Only $47 \%$ of physicians were able to identify nocturnal wheeze. Difficulty in recognizing nocturnal wheeze demonstrates the need for a more objective tool to diagnose NA associated wheeze.

Inability to identify and communicate a child's nocturnal symptoms may lead to NA being left undiagnosed, impairing treatment and leading to negative quality of life consequences for the child. For instance, a lack of awareness of NA symptoms in stable and treated child asthmatics led to poorer sleep quality and impaired daytime activity (77). Furthermore, children with nocturnal symptoms have an increased risk for future adverse asthma events (65). Constant monitoring of NA symptoms in children is crucial in order to prevent future asthma events and protect against daytime sequela.

\section{NOCTURNAL ASTHMA ASSESSMENT}

Nocturnal asthma is monitored by a combination of clinical history, subjective self or parental questionnaires and spirometry. The use of only spirometry or clinical history consistently underestimated asthma severity in a study of children (78). As diurnal spirometry is impractical and self or parental reports may be inaccurate, NA requires a home-based objective tool to increase monitoring efficacy. This is especially important in rural and lowsocioeconomic areas where overnight clinical monitoring is problematic (79). Acoustic analysis of patients while they sleep allows for a non-invasive method for diagnosing and monitoring NA.

\section{SNORING TO ASSESS NOCTURNAL ASTHMA}

Snoring is correlated with NA symptoms in children $(80,81)$. Snoring may cause transfer of nasal mucus to the lower airway through upper airway vibration and increased suction pressures in the pharynx. This allergen-laden mucus may induce an asthmatic episode. However, snoring is found in many more asthma patients than those with NA. Teodoescu et al. found that while $55 \%$ of adult asthmatics reported daytime sleepiness, $84 \%$ reported snoring with $38 \%$ reporting habitual snoring (82). Lu et al. reported a highly significant correlation between snoring and asthma in preschool children indicating snoring could be used as a diagnostic symptom of NA (81). However, an asthma prevalence of $28 \%$ was reported while snoring was found in $10.5 \%$ of children. This indicates that snoring may too unspecific for NA diagnosis. Studies have not confirmed a snoring parameter (length, volume) that correlates to other NA symptoms or daytime consequences (83). The results indicate snoring alone is not appropriate for the assessment of NA.

\section{NOCTURNAL WHEEZE}

Wheezing is defined as a high to low-pitched continuous musical sound judged to be of significant duration (84). Wheezing with unforced breathing is associated with the severity of airflow obstruction and thus is a good determinant for assessing asthma control (85). In addition to asthma, wheezing in children may be triggered by acute determinants such as bronchitis, bacterial tracheitis, laryngotracheobronchitis or chronic causes such as GERD, cystic fibrosis, or bronchopulmonary dysplasia (86). Children with frequent wheezing symptoms but no asthma diagnosis experience illness-related morbidity similar to diagnosed asthmatics (87). Thus nocturnal wheezing, in the absence of asthma, requires adequate identification of the underlying health issue. A lag-time of approximately two years has been reported between the first recognition of wheeze and consulting a physician for treatment (88). This indicates a lack of public awareness of nocturnal wheezing and its effects on asthmatic control and overall quality of life. Education of general practitioners and patients is required so that wheezing is not overlooked and is treated as a symptom of a possible underlying health issue.

\section{NOCTURNAL WHEEZE TO ASSESS NOCTURNAL ASTHMA}

Measurement of nocturnal wheeze has been employed as a non-invasive technique to assess NA $(89,90)$. Kiyokawa et al. recorded intermittent tracheal sounds in asthmatic patients and controls during sleep (91). A respiratory physician performed an auditory review and manually recorded the presence of wheezes. Although time consuming for the analyst, this method provided objective home-based information that positively correlated with subjective symptoms and inversely correlated with morning PEF. Many characteristics of 
wheezes, such as amplitude, frequency range, number of simultaneous wheezes, duration and chest distribution can be recorded and measured. The parameter that best correlates with other clinical indices of asthma is total wheeze duration as a percentage of sleep (92). The use of computerized automatic acoustic monitoring devices allows for objective wheeze detection without a physician reviewing nocturnal recordings. Computerized monitoring of the percent of sleep spent in wheeze, irrespective of the respiratory phase or site, was employed as the quantitative measurement in children and produced objective results with good sensitivity (93). The same wheeze monitoring method established that the presence of wheeze correlates to less than $51 \%$ of the expected morning FEV1 and a large diurnal variation in FEV1 (94). Although not used for the diagnosis of NA, lung sound analysis with computerized analysis of wheezing and crackles was suitable for the diagnosis of bronchiolitis in infants (95). The use of computerized acoustic analysis of nocturnal wheeze is an objective, home-based method that can be used in the determination of NA and other pulmonary disorders.

\section{SLEEP QUALITY OF NOCTURNAL ASTHMA PATIENTS}

In stable diagnosed child asthmatics, knowledge of NA symptoms is required in order to properly medicate the patient and to accurately assess daytime psychological impairments which may result from poor sleep quality. Nocturnal symptoms such as wheezing, cough, sleep disturbances and daytime sleepiness are reported significantly more in stable asthmatic children with non-diagnosed NA than in non-asthmatic controls (77). Accordingly, children with well-controlled, stable asthma have poorer quality of sleep and lower morning PEF values correlating to inferior objective and subjective sleep measurement as compared to nonasthmatic matched controls (96). In children with NA there is no difference in REM latency, REM sleep, sleep latency, total sleep time, and percentage in sleep stages as compared to controls (1). This indicates that the problems are not due to sleep stage quantity but rather to sleep quality since children with NA have more sleep awakenings than non-asthmatics $(77,97,98)$. This not only places strain on the child, but also on the family as awakenings are linked to a decrease in parental mood and an increase in perceived parenting hassles (99).

\section{SIGNIFICANCE OF WHEEZE ON SLEEP QUALITY}

Wheezing caused by NA correlates to an increase in the symptoms associated with disturbed sleep in both adults and children (100). Wheezing children are two times more at risk of having difficulties falling asleep and five times more likely to have restless sleep than non-wheezing children (100). In accordance, wheezing children are nearly four times more at risk of having daytime sleepiness than non-wheezing children (100). Importantly, children with nocturnal wheeze reported a higher number of nocturnal awakenings with a corresponding increase in daytime sleepiness as compared to non-wheezing controls (101). This underscores the importance of wheeze detection as a tool to monitor sleep-related behavioral problems in children.

\section{EFFECT OF NOCTURNAL ASTHMA ON CHILDHOOD DEVELOPMENT}

Children with NA report a higher incidence of disturbed sleep-associated symptoms such as vasomotor and memory deficits, depression, anxiety and daytime sleepiness (2). A study of over 100,000 children, ages $0-17$, found a significant correlation between asthma and developmental, emotional, and behavioral problems (102). It can be assumed from studies documenting the rates of undiagnosed NA in the general pediatric population that a significant proportion of the population studied suffered from NA $(6,103)$. Further contributing to the education problems of child NA sufferers, Diette et al. noted children with awakenings due to NA had a greater number of school absences with parents having an increased number of missed workdays (104).

\section{CONCLUSIONS}

Children with NA are not suitably monitored and thus are not receiving adequate care (87). Untreated NA leads to both negative physical and developmental consequences in children. Patient-centered measures for a child's asthma control are vital for improved asthma management (105). Proper asthma control requires patients and physicians to be familiar with NA symptoms. An automated wheeze detection device allows objective measurement of an important NA symptom that is correlated to reduced morning spirometry values. A low-cost wheeze detection device to identify and monitor NA is especially important in lower socioeconomic environments where health care access is limited, asthma rates are higher and parental reports of symptoms less reliable than more affluent areas. Additionally, detection of nocturnal wheeze in children will aid in the diagnosis and monitoring of numerous other respiratory pathologies. Future studies should analyze the appropriateness and cost/benefit of nocturnal wheeze detection for NA identification and asthma control. 


\section{ACKNOWLEDGEMENTS}

The author wishes to acknowledge Dr. Noam Gavriely for his encouragement in submitting this paper.

\section{REFERENCES}

1. Braman SS. The global burden of asthma. Chest. 2006 Jul;130(1 Suppl):4S-12S.

2. Stores G, Ellis AJ, Wiggs L, et al. Sleep and psychological disturbance in nocturnal asthma. Archives of disease in childhood. 1998 May;78(5):413-9.

3. Skloot GS. Nocturnal asthma: mechanisms and management. The Mount Sinai journal of medicine, New York. 2002 May;69(3):140-7.

4. Meijer GG, Postma DS, Wempe JB, et al. Frequency of nocturnal symptoms in asthmatic children attending a hospital out-patient clinic. Eur Respir J. 1995 Dec;8(12):2076-80.

5. Turner-Warwick M. Epidemiology of nocturnal asthma. The American journal of medicine. 1988 Jul 29;85(1B):6-8.

6. Raherison C, Abouelfath A, Le Gros V, et al. Underdiagnosis of nocturnal symptoms in asthma in general practice. J Asthma. 2006 Apr;43(3):199-202.

7. Sutherland ER. Nocturnal asthma: underlying mechanisms and treatment. Current allergy and asthma reports. 2005 Mar;5(2):161-7.

8. Syabbalo N. Chronobiology and chronopathophysiology of nocturnal asthma. International journal of clinical practice. 1997 Oct;51(7):455-62

9. van Aalderen WM, Meijer GG, Oosterhoff Y, et al. Epidemiology and the concept of underlying mechanisms of nocturnal asthma. Respiratory medicine. 1993 Aug;87 Suppl B:37-9.

10. Stephenson R. Circadian rhythms and sleep-related breathing disorders. Sleep medicine. 2007 Sep;8(6):681-7.

11. Ballard RD, Saathoff MC, Patel DK, et al. Effect of sleep on nocturnal bronchoconstriction and ventilatory patterns in asthmatics. J Appl Physiol. 1989 Jul;67(1):243-9.

12. Hetzel MR, Clark TJ. Does sleep cause nocturnal asthma? Thorax. 1979 Dec;34(6):749-54

13. Chan CS, Woolcock AJ, Sullivan CE. Nocturnal asthma: role of snoring and obstructive sleep apnea. The American review of respiratory disease. 1988 Jun;137(6):1502-4.

14. Whyte KF, Douglas NJ. Posture and nocturnal asthma. Thorax. 1989 Jul;44(7):579-81.

15. Greenough A, Everett L, Pool J, et al. Relation between nocturnal symptoms and changes in lung function on lying down in asthmatic children. Thorax. 1991 Mar;46(3):193-6.

16. Sontag SJ, O'Connell S, Khandelwal S, et al. Most asthmatics have gastroesophageal reflux with or without bronchodilator therapy. Gastroenterology. 1990 Sep;99(3):613-20.

17. Harding SM. Nocturnal asthma: role of nocturnal gastroesophageal reflux. Chronobiology international. 1999 Sep;16(5):641-62.

18. Kieckhefer GM, Lentz MJ. Nocturnal asthma in children. Advance for nurse practitioners. 2006 Jan;14(1):53-6.

19. Fix A, Sexton M, Langenberg P, et al. The association of nocturnal asthma with asthma severity. $\mathrm{J}$ Asthma. 1997;34(4):329-36.

20. Colice GL, Burgt JV, Song J, et al. Categorizing asthma severity. American journal of respiratory and critical care medicine. 1999 Dec;160(6):1962-7.

21. Contopoulos-Ioannidis DG, Manoli EN, Ioannidis JP. Metaanalysis of the association of beta2-adrenergic receptor polymorphisms with asthma phenotypes. The Journal of allergy and clinical immunology. 2005 May;115(5):963-72.
22. Yin K, Zhang X, Qiu Y. Association between beta2-adrenergic receptor genetic polymorphisms and nocturnal asthmatic patients of Chinese Han nationality. Respiration; international review of thoracic diseases. 2006;73(4):464-7.

23. Shigemitsu H, Afshar K. Nocturnal asthma. Current opinion in pulmonary medicine. 2007 Jan;13(1):49-55.

24. Hetzel MR, Clark TJ, Branthwaite MA. Asthma: analysis of sudden deaths and ventilatory arrests in hospital. British medical journal. 1977 Mar 26;1(6064):808-11.

25. Calhoun WJ. Nocturnal asthma. Chest. 2003 Mar;123(3 Suppl):399S-405S

26. de Marco R, Locatelli F, Cazzoletti L, et al. Incidence of asthma and mortality in a cohort of young adults: a 7-year prospective study. Respiratory research. 2005;6:95.

27. Tough SC, Hessel PA, Ruff M, et al. Features that distinguish those who die from asthma from community controls with asthma. J Asthma. 1998;35(8):657-65.

28. Jarjour NN, Busse WW, Calhoun WJ. Enhanced production of oxygen radicals in nocturnal asthma. The American review of respiratory disease. 1992 Oct;146(4):905-11.

29. Beasley R, Crane J, Lai CK, et al. Prevalence and etiology of asthma. The Journal of allergy and clinical immunology. 2000 Feb;105(2 Pt 2):S466-72.

30. Johnson CC, Ownby DR, Zoratti EM, et al. Environmental epidemiology of pediatric asthma and allergy. Epidemiologic reviews. 2002;24(2):154-75.

31. Burr ML, Wat D, Evans C, et al. Asthma prevalence in 1973, 1988 and 2003. Thorax. 2006 Apr;61(4):296-9.

32. Beuther DA, Sutherland ER. Overweight, obesity, and incident asthma: a meta-analysis of prospective epidemiologic studies. American journal of respiratory and critical care medicine. 2007 Apr 1;175(7):661-6.

33. Sithole F, Douwes J, Burstyn I, et al. Body mass index and childhood asthma: a linear association? J Asthma. 2008 Aug;45(6):473-7.

34. Seidell JC. Epidemiology of obesity. Seminars in vascular medicine. 2005 Feb;5(1):3-14.

35. Peters-Golden M, Swern A, Bird SS, et al. Influence of body mass index on the response to asthma controller agents. Eur Respir J. 2006 Mar;27(3):495-503.

36. Bellia V, Pistelli R, Filippazzo G, et al. Prevalence of nocturnal asthma in a general population sample: determinants and effect of aging. J Asthma. 2000;37(7):595-602.

37. Trends in aging--United States and worldwide. Mmwr. 2003 Feb 14;52(6):101-4, 6

38. Rona RJ, Chinn S, Burney PG. Trends in the prevalence of asthma in Scottish and English primary school children 198292. Thorax. 1995 Sep;50(9):992-3.

39. Pearce N, Ait-Khaled N, Beasley R, et al. Worldwide trends in the prevalence of asthma symptoms: phase III of the International Study of Asthma and Allergies in Childhood (ISAAC). Thorax. 2007 Sep;62(9):758-66.

40. Garner R, Kohen D. Changes in the prevalence of asthma among Canadian children. Health reports / Statistics Canada, Canadian Centre for Health Information = Rapports sur la sante / Statistique Canada, Centre canadien d'information sur la sante. 2008 Jun;19(2):45-50.

41. Ng Man Kwong G, Das C, Proctor AR, et al. Diagnostic and treatment behaviour in children with chronic respiratory symptoms: relationship with socioeconomic factors. Thorax. 2002 Aug;57(8):701-4.

42. Morgan AD, Rhind GB, Connaughton JJ, et al. Breathing patterns during sleep in patients with nocturnal asthma. Thorax. 1987 Aug;42(8):600-3.

43. Lavie L. Sleep-disordered breathing and cerebrovascular disease: a mechanistic approach. Neurologic clinics. 2005 
Nov:23(4):1059-75.

44. Irvin CG, Pak J, Martin RJ. Airway-parenchyma uncoupling in nocturnal asthma. American journal of respiratory and critical care medicine. 2000 Jan;161(1):50-6.

45. Quanjer PH, Lebowitz MD, Gregg I, et al. Peak expiratory flow: conclusions and recommendations of a Working Party of the European Respiratory Society. The European respiratory journal. $1997 \mathrm{Feb}$;24:2S-8S.

46. Redline S, Wright EC, Kattan M, et al. Short-term compliance with peak flow monitoring: results from a study of inner city children with asthma. Pediatric pulmonology. 1996 Apr;21(4):203-10.

47. Kamps AW, Roorda RJ, Brand PL. Peak flow diaries in childhood asthma are unreliable. Thorax. 2001 Mar;56(3):1802 .

48. Brouwer AF, Roorda RJ, Brand PL. Home spirometry and asthma severity in children. Eur Respir J. 2006 Dec;28(6):11317 .

49. Wensley DC, Silverman M. The quality of home spirometry in school children with asthma. Thorax. 2001 Mar;56(3):183-5.

50. Thompson R, Delfino RJ, Tjoa T, et al. Evaluation of daily home spirometry for school children with asthma: new insights. Pediatric pulmonology. 2006 Sep;41(9):819-28.

51. Mallol J, Castro-Rodriguez JA. Differences in prevalence of asthma, rhinitis, and eczema between parental and selfcompleted questionnaires in adolescents. Pediatric

52. Falconer A, Oldman C, Helms P. Poor agreement between reported and recorded nocturnal cough in asthma. Pediatric pulmonology. 1993 Apr;15(4):209-11.

53. Storms WW, Bodman SF, Nathan RA, et al. Nocturnal asthma symptoms may be more prevalent than we think. J Asthma. 1994;31(4):313-8.

54. Laforest L, Van Ganse E, Devouassoux G, et al. Asthmatic patients' poor awareness of inadequate disease control: a pharmacy-based survey. Ann Allergy Asthma Immunol. 2007 Feb;98(2):146-52.

55. Steenhuis TJ, Landstra AM, Verberne AA, et al. When Asthma Interrupts Sleep in Children: What is the Best Strategy? BioDrugs. 1999 Dec;12(6):431-8.

56. Inkelas M, Garro N, McQuaid EL, et al. Race/ethnicity, language, and asthma care: findings from a 4-state survey. Ann Allergy Asthma Immunol. 2008 Feb;100(2):120-7.

57. Chan KS, Keeler E, Schonlau M, et al. How do ethnicity and primary language spoken at home affect management practices and outcomes in children and adolescents with asthma? Archives of pediatrics \& adolescent medicine. 2005 Mar;159(3):283-9.

58. Levy ML, Godfrey S, Irving CS, et al. Wheeze detection: recordings vs. assessment of physician and parent. J Asthma. 2004;41(8):845-53.

59. Shalla V, Schellenberg G, Statistics Canada., et al. The value of words : literacy and economic security in Canada. Ottawa: Statistics Canada 1998.

60. DeWalt DA, Dilling MH, Rosenthal MS, et al. Low parental literacy is associated with worse asthma care measures in children. Ambul Pediatr. 2007 Jan-Feb;7(1):25-31.

61. Duran-Tauleria E, Rona RJ, Chinn S, et al. Influence of ethnic group on asthma treatment in children in 1990-1: national cross sectional study. BMJ (Clinical research ed. $1996 \mathrm{Jul}$ 20;313(7050):148-52.

62. de Lourdes Drachler M, de Castro Aerts DG, de Souza RM, et al. Social inequalities in maternal opinion of child development in southern Brazil. Acta Paediatr. 2005 Aug;94(8):1137-9.

63. Remes ST, Pekkanen J, Remes K, et al. In search of childhood asthma: questionnaire, tests of bronchial hyperresponsiveness, and clinical evaluation. Thorax. 2002 Feb;57(2):120-6.
64. Olson LM, Radecki L, Frintner MP, et al. At what age can children report dependably on their asthma health status? Pediatrics. 2007 Jan;119(1):e93-102.

65. Fuhlbrigge AL, Weiss ST, Kuntz KM, et al. Forced expiratory volume in 1 second percentage improves the classification of severity among children with asthma. Pediatrics. 2006 Aug;118(2):e347-55.

66. McCoy K, Shade DM, Irvin CG, et al. Predicting episodes of poor asthma control in treated patients with asthma. The Journal of allergy and clinical immunology. 2006 Dec;118(6):1226-33.

67. Kothare SV, Kaleyias J. The clinical and laboratory assessment of the sleepy child. Seminars in pediatric neurology. 2008 Jun;15(2):61-9.

68. Chervin RD, Archbold KH, Panahi P, et al. Sleep problems seldom addressed at two general pediatric clinics. Pediatrics. 2001 Jun;107(6):1375-80.

69. Brooke AM, Lambert PC, Burton PR, et al. Night cough in a population-based sample of children: characteristics, relation to symptoms and associations with measures of asthma severity. Eur Respir J. 1996 Jan;9(1):65-71.

70. Hublet A, Bacquer DD, Vereecken C, et al. Value of a shortened questionnaire in the description of asthma in 10-12-year-old pupils. Pediatr Allergy Immunol. 2004 Jun;15(3):247-52.

71. Hoek G, Wypij D, Brunekreef B. Self-reporting versus parental reporting of acute respiratory symptoms of children and their relation to pulmonary function and air pollution. International journal of epidemiology. 1999 Apr;28(2):293-9.

72. Decker K, Meyer K, Littlefield D, et al. Similar asthma prevalence estimates obtained from preadolescent and parent survey responses. Journal of clinical epidemiology. 2008 Jun;61(6):611-6.

73. Wittich AR, Li Y, Gerald LB. Comparison of parent and student responses to asthma surveys: students grades 1-4 and their parents from an urban public school setting. The Journal of school health. 2006 Aug;76(6):236-40.

74. Guyatt GH, Juniper EF, Griffith LE, et al. Children and adult perceptions of childhood asthma. Pediatrics. 1997 Feb;99(2):165-8.

75. Riedler J, Reade T, Dalton M, et al. Hypertonic saline challenge in an epidemiologic survey of asthma in children. American journal of respiratory and critical care medicine. 1994 Dec;150(6 Pt 1):1632-9.

76. Van Sickle D. Perceptions of asthma among physicians: an exploratory study with the ISAAC video. Eur Respir J. 2005 Nov;26(5):829-34.

77. Chugh IM, Khanna P, Shah A. Nocturnal symptoms and sleep disturbances in clinically stable asthmatic children. Asian Pacific journal of allergy and immunology / launched by the Allergy and Immunology Society of Thailand. 2006 JunSep;24(2-3):135-42.

78. Cowen MK, Wakefield DB, Cloutier MM. Classifying asthma severity: objective versus subjective measures. J Asthma. 2007 Nov;44(9):711-5.

79. Beard JR, Tomaska N, Earnest A, et al. Influence of socioeconomic and cultural factors on rural health. The Australian journal of rural health. 2009 Feb;17(1):10-5.

80. Bidad K, Anari S, Aghamohamadi A, et al. Prevalence and correlates of snoring in adolescents. Iranian journal of allergy, asthma, and immunology. 2006 Sep;5(3):127-32.

81. Lu LR, Peat JK, Sullivan CE. Snoring in preschool children: prevalence and association with nocturnal cough and asthma. Chest. 2003 Aug;124(2):587-93.

82. Teodorescu M, Consens FB, Bria WF, et al. Correlates of daytime sleepiness in patients with asthma. Sleep medicine. 2006 Dec;7(8):607-13.

83. Dalmasso F, Prota R. Snoring: analysis, measurement, clinical 
implications and applications. Eur Respir J. 1996 Jan;9(1):14659.

84. Loudon RG. Auscultation of the lung. Clinical notes on respiratory diseases. 1982 Fall;21(2):3-7.

85. Marini JJ, Pierson DJ, Hudson LD, et al. The significance of wheezing in chronic airflow obstruction. The American review of respiratory disease. 1979 Nov;120(5):1069-72.

86. Castro-Rodriguez JA, Garcia-Marcos L. Wheezing and Asthma in childhood: an epidemiology approach. Allergologia et immunopathologia. 2008 Sep-Oct;36(5):280-90.

87. Yeatts K, Davis KJ, Sotir M, et al. Who gets diagnosed with asthma? Frequent wheeze among adolescents with and without a diagnosis of asthma. Pediatrics. 2003 May;111(5 Pt 1):104654.

88. Wright AL, Stern DA, Kauffmann F, et al. Factors influencing gender differences in the diagnosis and treatment of asthma in childhood: the Tucson Children's Respiratory Study. Pediatric pulmonology. 2006 Apr;41(4):318-25.

89. Gross V, Reinke C, Dette F, et al. Mobile nocturnal long-term monitoring of wheezing and cough. Biomedizinische Technik. 2007;52(1):73-6.

90. Lenclud C, Cuttitta G, Van Gansbeke D, et al. Evaluation of nocturnal bronchoconstriction by all night tracheal sound monitoring. Thorax. 1996 Jul;51(7):694-8.

91. Kiyokawa H, Yonemaru M, Horie S, et al. Detection of nocturnal wheezing in bronchial asthma using intermittent sleep tracheal sounds recording. Respirology (Carlton, Vic. 1999 Mar;4(1):37-45

92. Baughman RP, Loudon RG. Lung sound analysis for continuous evaluation of airflow obstruction in asthma. Chest. 1985 Sep;88(3):364-8.

93. Bentur L, Beck R, Shinawi M, et al. Wheeze monitoring in children for assessment of nocturnal asthma and response to therapy. Eur Respir J. 2003 Apr;21(4):621-6.

94. Bentur L, Beck R, Irving $C$, et al. Nocturnal Wheeze Measurement in Young Asthmatics. Pediatr Asthma, Allergy \& Immunology. 2004 Oct;17(3):191-7.
95. Beck R, Elias $\mathrm{N}$, Shoval $\mathrm{S}$, et al. Computerized acoustic assessment of treatment efficacy of nebulized epinephrine and albuterol in RSV bronchiolitis. BMC pediatrics. 2007;7:22.

96. Sadeh A, Horowitz I, Wolach-Benodis L, et al. Sleep and pulmonary function in children with well-controlled, stable asthma. Sleep. 1998 Jun 15;21(4):379-84.

97. Janson C, De Backer W, Gislason T, et al. Increased prevalence of sleep disturbances and daytime sleepiness in subjects with bronchial asthma: a population study of young adults in three European countries. Eur Respir J. 1996 Oct;9(10):2132-8.

98. Janson C, Gislason T, Boman G, et al. Sleep disturbances in patients with asthma. Respiratory medicine. 1990 Jan;84(1):3742.

99. Fiese BH, Winter MA, Sliwinski M, et al. Nighttime waking in children with asthma: an exploratory study of daily fluctuations in family climate. J Fam Psychol. 2007 Mar;21(1):95-103.

100. Desager KN, Nelen V, Weyler JJ, et al. Sleep disturbance and daytime symptoms in wheezing school-aged children. Journal of sleep research. 2005 Mar;14(1):77-82.

101. Verhulst SL, Vekemans K, Ho E, et al. Is wheezing associated with decreased sleep quality in Sri Lankan children? A questionnaire study. Pediatric pulmonology. 2007 Jul;42(7):57983.

102. Blackman JA, Gurka MJ. Developmental and behavioral comorbidities of asthma in children. J Dev Behav Pediatr. 2007 Apr;28(2):92-9.

103. Turner-Warwick M. Nocturnal asthma: a study in general practice. The Journal of the Royal College of General Practitioners. 1989 Jun;39(323):239-43.

104. Diette GB, Markson L, Skinner EA, et al. Nocturnal asthma in children affects school attendance, school performance, and parents' work attendance. Archives of pediatrics \& adolescent medicine. 2000 Sep;154(9):923-8.

105. Gandhi RK, Blaiss MS. What are the best estimates of pediatric asthma control? Current opinion in allergy and clinical immunology. 2006 Apr;6(2):106-12.

Darrell Ginsberg is a B.Sc graduate from the University of Western Ontario currently completing his M.Sc at the Technion - Israel Institute of Technology in the Lloyd Rigler Sleep Apnea Laboratory under the supervision of Drs. Lena and Peretz Lavie. Darrell is looking forward to continuing his studies in the field of medicine. His research interests include sleep apnea, respirology and immunology. 